\title{
Atividade Antifúngica de Óleos Essenciais em Cepa de Aspegillus Flavus Link com Leitura por Medição e Imagem.
}

\section{Teresa Cristina Castilho Gorayeb (II), Giulliana Tornelli Lucas (III), Juliana Takemato Arakaki (II), João Cláudio Thoméo (II)}

(II) UNESP/IBILCE - Universidade Estadual Paulista (Rua Cristóvão Colombo 2265, 15054-000

São José do Rio Preto, São Paulo, Brasil ), (III) Fatec - Rio Preto - Faculdade de Tecnologia de São José do Rio Preto (R Fernandópolis, 2510, Eldorado - São José do Rio Preto/SP Brasil CEP 15043-020)

\section{Resumo}

Atualmente, existem vários métodos para avaliar a atividade antifúngica dos óleos essenciais de plantas, sendo estarealizada através da determinação de uma pequena quantidade da substância necessária para inibir o crescimento do microrganismo-teste; esse valor é conhecido como Concentração Mínima Inibitória (CMI). O método de difusão em placas é um método físico, no qual ummicrorganismo é desafiado contra uma substânciabiologicamente ativa em meio de cultura sólida erelaciona o tamanho da zona de inibição deste microrganismo desafiado, sendo que essas mediçõessão realizadas com o uso de paquímetro no diâmetro da colônia do fungo e consequentemente podem ocorrer erros nas leituras. Neste contexto o objetivo deste trabalho foi comparar a eficiência das medições das colônias com o uso do paquímetro e com a leitura da área da colônia por meio de imagens, realizadas por fotos e interpretadas pelo software Lenseye que determina a área da colônia formada pelo fungo.Foi testado o fungo Aspergillus flavus Link contra os óleos essenciais de canela (Cinnamomum zeylanicum), cravo-da-índia (Syzygium aromaticum), manjericão (Ocimum basilicum), orégano (Origanum vulgare) e capim limão (Cymbopogon citratus) adquiridos no mercado local. As avaliações da inibição do crescimento micelial foram realizadas em meio de cultura Batata - Dextrose - Agar (BDA), adicionados dos óleos nas concentrações de $0,50,100,250,500,1000$ e $2000 \mu \mathrm{g} / \mathrm{mL}$, após a solidificação do meio

\footnotetext{
Referência:

Teresa Cristina Castilho Gorayeb, Giulliana Tornelli Lucas, Juliana Takemato Arakaki, João Cláudio Thoméo. Atividade Antifúngica de Óleos Essenciais em Cepa de Aspegillus Flavus Link com Leitura por Medição e Imagem.. In: Anais do 12을 Congresso Latinoamericano de Microbiologia e Higiene de Alimentos - MICROAL 2014 [= Blucher Food Science Proceedings, num.1, vol.1]. São Paulo: Editora Blucher, 2014. DOI $10.5151 /$ foodsci-microal-252
} 
foi feito a perfuração de um poço central de $3 \mathrm{~mm}$, onde foram colocados $10 \mu \mathrm{L}$ de suspensão de106 esporos/mL de Aspergillus flavus Link e incubados por sete dias à $25 \pm 1^{\circ} \mathrm{C}$. Após este período foram realizadas as medições com o paquímetro do diâmetro da colônia e em seguida a placa foi fotografada e a imagem transferida para o software Lenseye que quantifica a área do crescimento fúngico capturada pela imagem. $\mathrm{O}$ resultado da CIM para o óleo de canela foi de 100 \% na concentração de $250 \mu \mathrm{g} / \mathrm{mL}$, ao comparar os resultados na concentração de $100 \mu \mathrm{g} / \mathrm{mL}$, que foram de 40,52\% para leitura com o paquímetro e 52,56\% para a leitura com a imagem, pode-se assim observar que a leitura pelo método de imagem mostrou uma maior exatidão aos dados obtidos o com contraste suficiente para verificar a real inibição dofungo. Para os outros óleos a CIM observada pela a imagem foi de 37,79\% na concentração de $250 \mu \mathrm{g} / \mathrm{mL}$, no óleo de cravo, para o de Capim cidreira foi de $89,34 \%$ na concentração de $500 \mu \mathrm{g} / \mathrm{mL}$, no de orégano foi de $80,17 \%$ na concentração de $500 \mu \mathrm{g} / \mathrm{mL}$ e no manjericão foi de $95,97 \%$ na concentração de $2000 \mu \mathrm{g} / \mathrm{mL}$. Com estes resultados pode-se inferir que o óleo de canela é um produto natural em destaque para utilização contra o Aspergillus flavus L e que a leitura por meio de imagem proporciona uma maior segurança nos dados obtidos.

Palavras-Chave: Amendoim, Lenseye, Biofungicidas, Óleos essenciais Agência de Fomento: 